\title{
Molecular Characterization of Prostate Cancer in Middle Eastern Population Highlights Differences with Western Populations with Prognostic Implication
}

\author{
Ramy A. Abdelsalam \\ University of Calgary Cumming School of Medicine \\ Ibrahim Khalifeh
}

AUB

Alan Box

University of Calgary Cumming School of Medicine

Maria Kalantarian

University of Calgary Cumming School of Medicine

\section{Sunita Ghosh}

Alberta Health Services

Hatem Abou-Ouf

University of Calgary Cumming School of Medicine

Tamara Lotfi

AUB

Mohammed Shahait

AUB

Nallasivam Palanisamy

Henry Ford Health System

Tarek A. Bismar ( $\sim$ Tarek.Bismar@cls.ab.ca )

University of Calgary Cumming School of Medicine https://orcid.org/0000-0002-9190-5088

Research article

Keywords: ERG protein expression; PTEN; SPINK1, Immunohistochemistry; Middle Eastern; Gleason score; Biochemical recurrence

Posted Date: November 20th, 2019

DOI: https://doi.org/10.21203/rs.2.17590/v1 
License: (c) (i) This work is licensed under a Creative Commons Attribution 4.0 International License. Read Full License

Version of Record: A version of this preprint was published at Journal of Cancer Research and Clinical Oncology on April 30th, 2020. See the published version at https://doi.org/10.1007/s00432-020-03221-x. 


\section{Abstract}

Background To investigate the incidence and prognostication of ERG, PTEN and SPINK1 protein expressions in prostate cancer cohort of Middle Eastern descent in comparison to published data from Western populationMethods Immunohistochemistry for ERG, PTEN and SPINK1 was performed in cohort of localized PCa $(n=340)$. Data correlated to pathological and clinical outcomes and compared to Western populations.Results ERG expression and PTEN loss noted in 123/288 (42.7\%) and 91/297 (30.6\%) of patients, respectively. SPINK1 expression assessed in subset of cases, noted in 6/150 (4\%) of patients. Only ERG expression was associated with grade groups, being more common in lower grade groups (1-3 vs 4-5; $p=0.04)$. In contrast to Western population, PTEN loss foci were more likely to be ERG negative, observed in $81 \%$ of tumor foci and patients with PTEN neg/ERG pos were more likely to exhibit biochemical recurrence (OR 2.831; $95 \% \mathrm{Cl}: 1.10-726, \mathrm{p}=0.03)$. This association remained significant in multivariate analysis (OR 2.68; $95 \% \mathrm{Cl}: 0.98-7.33, \mathrm{p}=0.05$ ), after adjusting for $\mathrm{GG}$, path stage and surgical margin.Conclusion This study documents significant differences in key molecular events in PCa in Middle Eastern population compared to Western populations that could explain differences in PCa incidence, progression and prognostication. ERG, PTEN and SPINK1 genomic alteration occur less frequently and the enrichment of ERG for PTEN loss is not observed. Additionally, patients with combined PTEN loss/ERG positive are at highest rate for BCR vs North American Caucasian population where PTEN loss alone seems to be associated with the worst clinical outcome. The data presented here further support differences in clonal evolution between Middle Eastern and Western population in relation to PCa and add further insight to understanding PCa molecular pathways.

\section{Background}

The ability to predict disease progression and clinical outcome is a major issue in the management of prostate cancer (PCA) patients. Currently, predicting disease metastasis and clinical progression are one of the main challenges facing physicians in the management of PCA. Currently, several underlying molecular alterations suggested to reflect clonal heterogeneity are well characterized in PCA within North American and Western populations, including ERG, PTEN and SPINK1 among others [1].

Gene rearrangements between TMPRSS2, which is an androgen receptor-regulated gene located at (21q22.3) and members of ETS family of transcription factors, commonly ERG (21q22.2), are reflective of molecular subtypes of PCA and are proposed to be associated with specific downstream molecular alteration responsible for disease progression [2-5]. ERG, is the most common fusion partner of TMPRSS2 [6, 7] detected in approximately $50 \%$ of prostate-specific antigen (PSA) - screened prostate cancers [8]. ETS rearrangements also appear to be more common in peripheral zone than transition zone tumors [9]. However, the incidence and relation of such molecular alterations in different ethnic groups are not well characterized yielding conflicting results based on several published reports [10-12]. ERG has been suggested to be not prognostic in surgical cohorts compared to non-surgically treated cohorts such as those in active surveillance programs or watchful waiting [13-16]. The prevalence of ERG expression or gene rearrangements in western PCA population ranges from 50 to $70 \%$ with documented differences 
between Caucasian-Americans and African-Americans, with ERG being more frequent in CaucasianAmericans (41.9\% vs 23.9\%) [17]. In Chinese PCA populations, ERG was noted at much lower frequency of $\sim 14 \%$ [18]. Similar incidence was also observed in patients with Asian descent from Japan, Korea [19] and India [20].

One previous study performed in Middle East (Jordan) in 2017 with 193 prostatic cancer cases suggested ERG to be present in slightly lower incidence at $33.2 \%$ compared to Caucasian American [21].

PTEN is one of the most commonly inactivated tumor suppressor genes in prostate cancer [22] and PTEN genomic deletions or protein loss have been associated with several cancer progression including PCA [23-25]. Several studies have documented association between PTEN genomic deletions or protein loss and worse clinical outcome in PCA patients $[26,28,29]$ which has been gaining significant value in clinical practice given its potential endorsement by the Food and Drug Administration (FDA) as clinically valued biomarker in PCA [26]. Several studies have also documented association between ERG gene rearrangements/expression and increased incidence of PTEN deletions/loss of expression (i.e. there is enrichment of in PTEN deletion in tumor foci with ERG gene rearrangements (Bismar, et al. 2010) [23]. We also reported significant association of homozygous PTEN genomic deletions and ERG gene rearrangements with lymph node metastasis, hormone-refractory PCA and cancer-specific death [27].

The value for ERG/PTEN combined status remains controversial within different ethnicities, with one study from Brazil showing adverse clinical outcome in patients with ERG/PTEN combined genomic aberration, while several others from Western population documented this adverse outcome in patients with only PTEN deletions without ERG gene rearrangements, including one by our group [30, 31]. Furthermore, there is some support that $E R G$ gene rearrangements are more likely observed in lower grade tumors (grade groups 1-3) relative to higher grade ones (grade groups 4-5).

The serine peptidase inhibitor, Kazal type 1 (SPINK1) is a protein, regulated by androgens, overexpressed specifically in a subset of ETS-negative prostate cancers; its overexpression has been associated with decreased biochemical recurrence-free survival [32]. SPINK1 outlier expression has been identified in $\sim 10 \%$ of prostate cancers and appears to be mutually exclusive from ERG rearrangements [33].

Interestingly, patients harboring these tumors were found to have a shorter time to biochemical recurrence than patients who do not overexpress SPINK1. SPINK1 outlier status, independent of Gleason score, lymph node status, surgical margin status, seminal vesicle invasion, extracapsular extension, and preoperative PSA, has been shown to be a significant predictor of clinical recurrence[33]. SPINK1 is an extracellular secreted protein and therefore is amenable to both therapeutic targeting and non-invasive diagnosis [34]. Only two studies have reported SPINK1 expression in ductal adenocarcinoma of the prostate. They observed that SPINK1 is expressed in about $25 \%$ of ductal adenocarcinoma cases and expressed in subset of ETS-negative PCA, and has been associated with aggressiveness [35, 36]. Another 
study performed by Pallavi, et al endorsed that SPINK1 is expressed in $22.7 \%$ of pure ductal adenocarcinoma and in $43.5 \%$ of mixed ductal and adenocarcinoma [37]. On the other hand, SPINK1 status showed mixed results in relation to patient's prognosis based on several published reports[35, 38].

Herein, we comprehensively characterized ERG, PTEN and SPINK1 expression using combined IHC in a cohort of men with PCA patients from Middle Eastern population, who were treated by radical prostatectomy as single therapy. We assessed the incidence, overlap and prognostication of individual and combined markers in relation to key clinical and pathological parameter.

\section{Methods}

\section{Study population:}

Our study population consisted of 340 men with PCA from 1998-2012 and who were managed by radical prostatectomies. Clinical information on follow-up was available for 329 patients collected through the AUB clinical Registry in relation to biochemical recurrence post radical prostatectomy. Five tissue microarrays (TMAs) were constructed with average four cores (range 2-6) for each patient using manual tissue microarrayer (Beecher Instruments, Silver Spring, MD). The University of Calgary Cumming School of Medicine institutional review board approved the study.

ERG, PTEN and SPINK1 status by immunohistochemistry (IHC)

We carried out a dual-color ERG/PTEN and ERG/SPINK1 IHC staining protocol as previously described $[39,40]$. The antibodies used were rabbit monoclonal [ERG at 1:100 dilution (Clone EPR 3864, Epitomics, Burlingame, CA, USA), PTEN monoclonal antibody (138G6, Cell Signaling Technology, Danvers, MA, USA) at 1:25 dilution and SPINK1 antibody (WH0006690M1, Clone 4D4, Sigma-Aldrich, St. Louis, MO, USA) at 1:25 dilution]. Negative control performed by substituting primary antibody with normal mouse prediluted serum at $1 / 200$.

\section{Pathological analysis}

All cases were re-reviewed and Gleason scores/groups were assessed by the study pathologists based on the 2014 WHO/ISUP criteria. The two common patterns were sampled on the TMAs for evaluation. Both ERG and SPINK1 intensities were assessed as (0; negative; 1, positive) based on previous correlation with $E R G$ rearrangement detected by FISH (data not shown). The expression of ERG in endothelial cells, acted as internal control being highly expressed. PTEN intensity was assessed as $(0$; negative, 1 ; weak, 2 ; moderate and 3; high), with high defined as intensity equal to benign adjacent epithelium. Furthermore, PTEN intensity was further analyzed as intact "positive" vs absent "negative" to avoid smaller numbers within subgroups. Figure 1 (A-D) shows examples of ERG, PTEN and SPINK1 protein expression using combined IHC method. 
Descriptive statistics were used to describe the study variables. Mean and standard deviation were reported for continuous variables and frequency and proportions for the categorical variables. Chi-square tests were to compare two categorical variables. Fisher's exact test were reported if the cell frequency were less than 5. Binary logistic regression analysis was used for the outcome variable PSA relapse (yes vs. no). Odds ratio (OR) and the corresponding $95 \%$ confidence intervals were reported. The association of the combined score of PTEN and ERG with PSA relapse were analyzed using univariate and multivariate models. For the multivariate model Gleason score, surgical margin and pathological stage were included in the analysis.

SPSS version 25 was used to conduct all the statistical analysis, a p-value $<0.05$ was used for statistical significance. Two sided tests were used for all the analysis.

\section{Results}

\section{Study Population}

\section{- Clinical features}

Median patients' age was 62 years (range 43-75). 115 of men (34\%) were GS=6, 180 (53\%) of GS=7, 26 (8\%) of GS=8 and $13(4 \%)$ of GS=9. $243(73 \%)$ of men were pT2 and $91(27 \%)$ of were pT3. 153 patients (45\%) had Positive surgical margins. Table 1 summarizes clinical and pathological characteristics.

\section{- PTEN, ERG and SPINK1 by immunohistochemistry}

ERG positivity was detected in 123/288 (42.7\%). PTEN protein expression was positive in 206/297 of cases with $(69.3 \%)$ ranging from weak to high intensity relative to adjacent benign prostate epithelium (control).

IHC for SPINK1 was successful for only 2 TMAs $(n=150)$ due to technical issues and was expressed in $6 / 150$ cases $(4 \%)$.

Although there was no significant association between individual grade grouping and each of ERG, PTEN and SPINK1 expression, there was significant correlation between ERG expression and Gleason score when assessed as GG1-3 vs $4-5$ with ERG positive cases occurring in $45 \%$ cases of GG1-3 vs. $27 \%$ in GG4$5(p=0.04)$. PTEN did not show any significant association within this distribution $(p=0.11)$. Table 2 summarizes distribution of PTEN, ERG and SPINK1 in various Gleason grade groups and as binary groups. 
- Combined makers by immunohistochemistry:

To gain insight into the co-expression of markers within same tumor foci, we investigated marker status based on the status within individual core tumor foci. In this cohort, 32/246 13\% tumor tissue cores were PTEN negative/ ERG positive, while 100/246 (41\%) of cores showed any PTEN intensity while being ERG negative.

In contrast to published reports from western population, tumors foci negative for PTEN staining were not enriched for ERG positivity and were more likely to be ERG negative $81 \%$ vs $61 \%$ ERG positive tumor foci being PTEN negative $(p=0.06)$ (Table 3$)$.

Characterizing combined PTEN and SPINK staining status, 29/207 (14\%) cores showed PTEN loss, of which 28/29 (96.5\%) cores were SPINK1 negative while 1/29 (3.5\%) cores was SPINK1 positive. PTEN positive expression was observed in 178/207 (86\%) cores, with 175/178 (98.3\%) cores being SPINK1 negative and $3 / 178(1.6 \%)$ being SPINK1 positive.

As reported before by our group, PTEN negative tumors were less likely to be SPINK1 positive (3.5\% in this cohort) (41).

Investigating combined ERG and SPINK1 staining, 44/217 (20\%) cores were ERG positive, non-of which was SPINK1 positive. On the other hand, $178 / 217$ (80\%) cores were ERG negative, 4 of which (2\%) were SPINK1 positive. These results confirm mutual exclusivity of ERG and SPINK1.

- Key Variable Distribution of Biomarkers stratified by Gleason grade Biochemical Recurrence

Due to subgroup size and to assess for association with BCR, PTEN was assessed as binary value PTEN negative (absence of staining) vs PTEN positive (presence of any staining). In univariate analysis, PTEN negative/ERG positive cases showed higher rates of BCR compared to any other combination (OR 2.831; $95 \% \mathrm{Cl}: 1.10-7.26, p=0.03)$ and remained significant in multivariate analysis after adjusting for Gleason grade grouping, surgical margins and pathological stage (OR 2.68; $95 \% \mathrm{Cl}=0.98-7.33), \mathrm{p}=0.05$ ) (Table 4$)$

No significant association was found between SPINK1 positive vs negative and BCR (data not shown).

\section{Discussion}

The epidemiology of PCA in Middle Eastern Arab populations are not well studied in contrast to North America and Western Europe. This is likely due to the absence of established PSA screening, lack of population-based registries, and existence of prospective oncology databases [41].

In this study, we assessed a large and more homogenous cohort of 340 radical prostatectomy and documented ERG expression to be present in $42 \%$ of PCA cases in Middle Eastern Arab population with prognostic implication in association to PTEN loss and SPINK1 expression. 
Although the rate of ERG expression detected in this study is at lower end of that observed in in North America and Western Europe, which is documented generally around $45 \%-50 \%$ [42], it is still significantly higher than those reported in Asian and African American populations of about $15 \%$ and $27 \%$ respectively $[43,44]$.

One earlier study by Aldaoud et al. reported on ERG expression in Middle Eastern population suggested the incidence to be lower among Arab population at 33.2\% compared to North American and European population and the study failed to document any prognostic value or association to Gleason grade grouping [21]. The reason for such discrepancy in incidence between our study and that of Aldaoud et al, is that they reported ERG incidence in mixed cases spanning peripheral zone (assessed through needle biopsy) and transition zone (assess by TURP). This is significant issue, as it is well known and documented by our group and others that ERG expression is significantly higher in peripheral zone tumors compared to those in transition zone [3], hence, combining both zones for reporting ERG incidence will artificially suggest lower incidence of ERG.

Loss of PTEN expression is well known to be associated with disease progression and patient's prognosis in several cancers and has also been implicated as potential targets for PI3K related therapies [21] and PTEN loss, as assessed by a validated and simple IHC protocol, was documented to be associated with a two-fold increase in risk of lethal progression independent of clinical-pathologic parameters [26]. Another study performed by Shan, et al in Arab men with PCA confirmed that PTEN is downregulated and associated with disease progression in PCA [45]. In the current study, the rate of PTEN loss was noted within the same range compared to Caucasian and African American cohorts, however, we did not observe significant association between loss of PTEN expression and increased Gleason grade grouping as suggested in North American and Western populations $(p=0.11)$,

Previous reports in Western and European cohorts suggested significant interplay between ERG positivity and PTEN loss with potential clinical value in various clinical scenarios. However, the prognostic value of combined ERG and PTEN have yielded mixed results. A study from Brazil showed that tumors which are PTEN deleted and ERG gene rearranged were more likely to exhibit biochemical relapse after radical prostatectomy relative to those with no genomic alterations for ERG and PTEN (i.e., not ERG rearranged and PTEN deleted). However, several subsequent studies in North American and European cohorts documented that prostate tumors with PTEN genomic alteration without ERG rearrangements (i.e., those with PTEN deletion or loss of protein expression) are associated with worse clinical outcome $[26,46,47]$. Our results in Middle Eastern cohort document higher BCR in PTEN neg/ERG pos tumors similar to the initial data from Brazil.

Similar to earlier reports in Western cohorts, we observed higher frequency of ERG expression in lower grade group 1-3 vs 4-5 ( $p=0.04)$. However, contrary to Western and European cohorts, our results in this Middle Eastern cohort, ERG positive foci were not enriched for PTEN genomic deletions as reflected by absence of PTEN staining, but showed non-significant trend $(p=0.06)$. 
Most studies reported that SPINK1 protein is detected in about 9\% of PCA cases of Caucasian cohorts vs $23 \%$ in African American with some suggestion of prognostic value[44, 48]. In our study, SPINK1 protein expression was noted at much lower incidence of only $4 \%$ which is significantly lower than those reported in Western population above. However, we did not observe any prognostic association for SPINK1 which may be due to the fact of lower-case number overall.

Previous studies found SPINK1 protein expression to be inversely associated with PTEN gene deletion and exclusive of loss of PTEN intensity [27] and positively associated with higher PTEN protein expression[49]. In this study we also observed notable inverse relation between PTEN negative intensity and SPINK positivity.

Although some recent studies have reported co-expression of ERG and SPINK1 in up to 4\% of prostate cancers[27, 41, 49], the majority of reports confirm ERG and SPINK1 being mutually exclusive[34], which was also noted in our study.

The above results indicate that molecular landscape of PCA in Middle Eastern population differs from other races. This might be explained by genetic differences, environmental, lifestyle and dietary factors, especially since it has been reported that gut microbiome reflective of diet may have a role on gene expression and cancer risk cancers[50].

The clinical value of our study stems from the fact that pathological staging system and Gleason score do not explain racial difference in PCA outcomes. Therefore, such markers may have a role in the future in personalizing prognosis estimates for patients and guide novel targeted treatment.

\section{Conclusions}

ERG, PTEN and SPINK1 status play significant role in PCA of Middle Eastern population with ERG being expressed at similar rates and SPINK1 expressed at significantly lower rates compared to Western population. However, in contrast, ERG foci are not enriched for PTEN loss with PTEN neg/ERG pos tumor present at higher frequency in advanced grade grouping and associated with increased risk of BCR. The differences in incidence and correlation between such markers, support different underlying molecular background in respect to ethnic background and highlights potential different biology in disease progression which warrant further investigation.

\section{Abbreviations}

PCA: Prostate Cancer

CRPC: Castrate resistant prostate cancer

ETS: Erythroblast transformation-specific

PTEN: Phosphatase and tensin homolog 
SPINK1: Serine protease inhibitor Kazal-type 1

BCR: Biochemical recurrence

\section{Declarations}

Ethical approval and consent to participate: The study was approved by the ethics review board of University of Calgary

- Ethics approval: The study was approved by the U Calgary Cumming School of Medicine ethics review board and in accordance with the 1964 Helsinki declaration and its later amendments or comparable ethical standards. Patient consent was waived by the ethics review board, due to the retrospective nature of the study.

- Consent for publication: Not applicable.

- Availability of data and materials: The study is retrospective with samples available from 1998-2008. Data sharing is not applicable.

- Competing interest: TAB is Editorial Board Member of BMC Cancer. Other authors have no conflict of interest to declare.

- Funding: This work was supported in part by the Prostate Cancer Foundation, USA

Young Investigator Award and Prostate Cancer Canada, Translational Acceleration Grant and by funds from Calgary Laboratory Services (T.A.B). The Agency provide operating cost funds with no effect on actual research design or outcome.

Authors' contributions: $R A, A B, M K, H A$ performed analysis, IK, TL, MS collected data and performed analysis, SG performed statistical analysis, NP performed, supervised and provided input for manuscript and marker staining. TAB supervised and planned study. All authors has approved the final version of this manuscript.

Acknowledgment: We thank Ms. Ruby Reyes for her technical assistance in preparing this manuscript.

\section{Tables}

Table 1: Patients' Demographics of the study Cohort 


\begin{tabular}{|l|l|}
\hline Variables & $\mathrm{N}(\%)$ \\
\hline Grade group/Gleason score & \\
\hline GG1 (GS6) & $115(34)$ \\
\hline GG2,3 GS7) & $180(53)$ \\
\hline GG4 (GS8) & $26(8)$ \\
\hline GG5 (GS9-10) & $13(4)$ \\
\hline Age & $62.1+/-5.96$ \\
\hline Biochemical Recurrence & \\
\hline Yes & $91(27)$ \\
\hline No & $213(63)$ \\
\hline Missing & $36(11)$ \\
\hline Stage & \\
\hline pT2 & $243(73)$ \\
\hline pT3 & $91(27)$ \\
\hline Surgical margin & \\
\hline neg & $181(55)$ \\
\hline pos & $153(45)$ \\
\hline
\end{tabular}

Table 2: Distribution of PTEN, ERG and SPINK1 in various Grade groups and in binary Gleason groups (GG $\leq 3$ vs $>3$ ) 


\begin{tabular}{|l|c|c|c|}
\hline Variables & PTEN Negative & PTEN Positive & p-value \\
\hline GS 6 & $27(29)$ & $35(71)$ & 0.29 \\
\hline GS $3+4$ & $32(32)$ & $69(68)$ & \\
\hline GS $4+3$ & $24(39)$ & $38(61)$ & \\
\hline GS 8 & $3(14)$ & $19(86)$ & \\
\hline GS 9 & $4(33)$ & $8(67)$ & \\
\hline GS <=7 & $83(32)$ & $173(68)$ & 0.11 \\
\hline GS $>7$ & $7(19)$ & $29(81)$ & \\
\hline Variables & ERG negative & ERG positive & p-value \\
\hline GS 6 & $50(54)$ & $43(46)$ & 0.16 \\
\hline GS $3+4$ & $49(53)$ & $44(47)$ & \\
\hline GS $4+3$ & $35(61)$ & $22(39)$ & \\
\hline GS 8 & $17(81)$ & $4(19)$ & \\
\hline GS 9 & $7(54)$ & $6(46)$ & \\
\hline GS <=7 & $135(55)$ & $110(45)$ & 0.04 \\
\hline GS >7 & $27(73)$ & $10(27)$ & \\
\hline Variables & SPINK Negative & SPINK Positive & p-value \\
\hline GS 6 & $40(28)$ & $3(50)$ & 0.25 \\
\hline GS $3+4$ & $55(38)$ & $2(33)$ & \\
\hline GS $4+3$ & $32(22)$ & $0(0)$ & \\
\hline GS 8 & $12(8)$ & $0(0)$ & \\
\hline GS 9 & $5(4)$ & $1(17)$ & \\
\hline GS <=7 & $127(87)$ & $5(83)$ & 0.57 \\
\hline GS $>7$ & $19(13)$ & $1(17)$ & \\
\hline
\end{tabular}

Table 3: Distribution of combined ERG/PTEN in Gleason grade groups

\begin{tabular}{|l|c|c|c|c|c|}
\hline Variables & $\begin{array}{c}\text { PTEN Neg/ ERG } \\
\text { Pos }\end{array}$ & $\begin{array}{c}\text { PTEN Neg/ ERG } \\
\text { Neg }\end{array}$ & $\begin{array}{c}\text { PTEN Pos/ ERG } \\
\text { Pos }\end{array}$ & $\begin{array}{c}\text { PTEN Pos/ ERG } \\
\text { Neg }\end{array}$ & p-value \\
\hline GS 6 & $6(8)$ & $17(24)$ & $28(39)$ & $21(29)$ & 0.06 \\
\hline GS 3+4 & $15(18)$ & $9(11)$ & $24(29)$ & $36(43)$ & \\
\hline GS $4+3$ & $9(18)$ & $8(16)$ & $10(20)$ & $23(46)$ & \\
\hline GS 8 & $0(0)$ & $3(15)$ & $4(20)$ & $13(65)$ & \\
\hline GS 9 & $2(17)$ & $2(17)$ & $4(33)$ & $4(33)$ & \\
\hline
\end{tabular}

Table 4: Univariate and multivariate analysis of combined status of ERG/PTEN in relation to Biochemical Recurrence 


\begin{tabular}{|l|l|l|c|}
\hline \multicolumn{1}{|c|}{ Variables } & \multicolumn{1}{c|}{ OR } & \multicolumn{1}{c|}{$95 \%$ CI } & p-value \\
\hline \multicolumn{2}{|l|}{ Univariate analysis of combined status of ERG/PTEN in relation to Biochemical Recurrence } \\
\hline Combined PTEN and ERG (PTEN Pos and ERG Neg) & & & \\
\hline PTEN Neg and ERG Pos & 2.831 & $1.10-7.26$ & 0.03 \\
\hline PTEN Neg and ERG Neg & 1.17 & $0.46-2.94$ & 0.74 \\
\hline PTEN Pos and ERG Pos & 1.41 & $0.68-2.92$ & 0.35 \\
\hline $\begin{array}{l}\text { Multivariate analysis of key pathological parameters and combined ERG/PTEN } \\
\text { recurrence }\end{array}$ & OR relation to biochemical \\
\hline \multicolumn{2}{|c|}{ Variables CI } & p-value \\
\hline Combined PTEN and ERG (PTEN Pos and ERG Neg) & & & \\
\hline Combined PTEN and ERG (PTEN Pos and ERG Neg) & & & \\
\hline PTEN Neg and ERG Pos & 2.68 & $0.98-7.33$ & 0.05 \\
\hline PTEN Neg and ERG Neg & 1.34 & $0.50-3.58$ & 0.56 \\
\hline PTEN Pos and ERG Pos & 1.08 & $0.49-2.35$ & 0.85 \\
\hline (GG4-5) Gleason Score >7 & & & \\
\hline (GG1-3) Gleason score $\leq 7$ & 0.31 & $0.14-0.72$ & 0.006 \\
\hline Pathology stage (pT2) & & & \\
\hline pT3 & 1.79 & $0.89-3.60$ & 0.10 \\
\hline Surgical Margin Neg & & & \\
\hline Surgical Margin Pos & 2.20 & $1.13-4.27$ & 0.02 \\
\hline
\end{tabular}

\section{References}

1. Shoag J, Barbieri CE: Clinical variability and molecular heterogeneity in prostate cancer. Asian J Androl 2016, 18(4):543-548.

2. Demichelis F, Fall K, Perner S, Andren O, Schmidt F, Setlur SR, Hoshida Y, Mosquera JM, Pawitan Y, Lee $C$ et al: TMPRSS2:ERG gene fusion associated with lethal prostate cancer in a watchful waiting cohort. Oncogene 2007, 26(31):4596-4599.

3. Liu S, Yoshimoto M, Trpkov K, Duan Q, Firszt M, Corcos J, Squire JA, Bismar TA: Detection of ERG gene rearrangements and PTEN deletions in unsuspected prostate cancer of the transition zone. Cancer Biol Ther 2011, 11(6):562-566.

4. Bismar TA, Dolph M, Teng LH, Liu S, Donnelly B: ERG protein expression reflects hormonal treatment response and is associated with Gleason score and prostate cancer specific mortality. Eur $J$ Cancer 2012, 48(4):538-546.

5. Tomlins SA, Palanisamy N, Siddiqui J, Chinnaiyan AM, Kunju LP: Antibody-Based Detection of ERG Rearrangements in Prostate Core Biopsies, Including Diagnostically Challenging Cases: ERG Staining in Prostate Core Biopsies. Arch Pathol Lab Med 2012, 136(8):935-946. 
6. Perner S, Mosquera JM, Demichelis F, Hofer MD, Paris PL, Simko J, Collins C, Bismar TA, Chinnaiyan AM, De Marzo AM et al: TMPRSS2-ERG fusion prostate cancer: an early molecular event associated with invasion. Am J Surg Pathol 2007, 31(6):882-888.

7. Tomlins SA, Rhodes DR, Perner S, Dhanasekaran SM, Mehra R, Sun XW, Varambally S, Cao X, Tchinda J, Kuefer R et al: Recurrent fusion of TMPRSS2 and ETS transcription factor genes in prostate cancer. Science 2005, 310(5748):644-648.

8. Perner S, Demichelis F, Beroukhim R, Schmidt FH, Mosquera JM, Setlur S, Tchinda J, Tomlins SA, Hofer MD, Pienta KG et al: TMPRSS2:ERG fusion-associated deletions provide insight into the heterogeneity of prostate cancer. Cancer Res 2006, 66(17):8337-8341.

9. Braun M, Scheble VJ, Menon R, Scharf G, Wilbertz T, Petersen K, Beschorner C, Reischl M, Kuefer R, Schilling $D$ et al: Relevance of cohort design for studying the frequency of the ERG rearrangement in prostate cancer. Histopathology 2011, 58(7):1028-1036.

10. Abou-Ouf H, Zhao L, Bismar TA: ERG expression in prostate cancer: biological relevance and clinical implication. J Cancer Res Clin Oncol 2016, 142(8):1781-1793.

11. Lee SL, Yu D, Wang C, Saba R, Liu S, Trpkov K, Donnelly B, Bismar TA: ERG Expression in Prostate Needle Biopsy: Potential Diagnostic and Prognostic Implications. Appl Immunohistochem Mol Morphol 2015, 23(7):499-505.

12. Teng LH, Wang C, Begin LR, Dolph M, Yilmaz A, Trpkov K, Donnelly B, Bismar TA: ERG protein expression and gene rearrangements are present at lower rates in metastatic and locally advanced castration-resistant prostate cancer compared to localized disease. Urology 2013, 82(2):394-399.

13. Huang KC, Alshalalfa M, Hegazy SA, Dolph M, Donnelly B, Bismar TA: The prognostic significance of combined ERG and androgen receptor expression in patients with prostate cancer managed by androgen deprivation therapy. Cancer Biol Ther 2014, 15(9):1120-1128.

14. Huang KC, Dolph M, Donnelly $B$, Bismar TA: ERG expression is associated with increased risk of biochemical relapse following radical prostatectomy in early onset prostate cancer. Clin Trans/ Oncol 2014, 16(11):973-979.

15. Teng LH, Wang C, Dolph M, Donnelly B, Bismar TA: ERG Protein Expression Is of Limited Prognostic Value in Men with Localized Prostate Cancer. ISRN Urol 2013, 2013:786545.

16. Dal Pra A, Lalonde E, Sykes J, Warde F, Ishkanian A, Meng A, Maloff C, Srigley J, Joshua AM, Petrovics $G$ et al: TMPRSS2-ERG status is not prognostic following prostate cancer radiotherapy: implications for fusion status and DSB repair. Clin Cancer Res 2013, 19(18):5202-5209.

17. Mani RS, lyer MK, Cao Q, Brenner JC, Wang L, Ghosh A, Cao X, Lonigro RJ, Tomlins SA, Varambally S et al: TMPRSS2-ERG-Mediated Feed-Forward Regulation of Wild-Type ERG in Human Prostate Cancers. Cancer research 2011, 71(16):5387-5392.

18. Jiang H, Mao X, Huang X, Zhao J, Wang L, Xu J, Zhang H, Lu Y, Yu Y: TMPRSS2:ERG fusion gene occurs less frequently in Chinese patients with prostate cancer. Tumour Biol 2016, 37(9):1239712402. 
19. Furusato B, van Leenders GJ, Trapman J, Kimura T, Egawa S, Takahashi H, Furusato M, Visakorpi T, Hano H: Immunohistochemical ETS-related gene detection in a Japanese prostate cancer cohort: diagnostic use in Japanese prostate cancer patients. Pathol Int 2011, 61(7):409-414.

20. Ateeq B, Kunju LP, Carskadon SL, Pandey SK, Singh G, Pradeep I, Tandon V, Singhai A, Goel A, Amit S et al: Molecular profiling of ETS and non-ETS aberrations in prostate cancer patients from northern India. Prostate 2015, 75(10):1051-1062.

21. Aldaoud N, Abdo N, Al Bashir S, Alqudah M, Marji N, Alzou'bi H, Alazab R, Trpkov K: Prostate cancer in Jordanian-Arab population: ERG status and relationship with clinicopathologic characteristics. Virchows Arch 2017, 471(6):753-759.

22. Grasso CS, Wu YM, Robinson DR, Cao X, Dhanasekaran SM, Khan AP, Quist MJ, Jing X, Lonigro RJ, Brenner JC et al: The mutational landscape of lethal castration-resistant prostate cancer. Nature 2012, 487(7406):239-243.

23. Bismar TA, Yoshimoto M, Vollmer RT, Duan Q, Firszt M, Corcos J, Squire JA: PTEN genomic deletion is an early event associated with ERG gene rearrangements in prostate cancer. BJU Int 2011, 107(3):477-485.

24. Facher EA, Law JC: PTEN and prostate cancer. J Med Genet 1998, 35(9):790.

25. Hyun T, Yam A, Pece S, Xie X, Zhang J, Miki T, Gutkind JS, Li W: Loss of PTEN expression leading to high Akt activation in human multiple myelomas. Blood 2000, 96(10):3560-3568.

26. Ahearn TU, Pettersson A, Ebot EM, Gerke T, Graff RE, Morais CL, Hicks JL, Wilson KM, Rider JR, Sesso HD et al: A Prospective Investigation of PTEN Loss and ERG Expression in Lethal Prostate Cancer. $J$ Natl Cancer Inst 2016, 108(2).

27. Huang KC, Begin LR, Palanisamy N, Donnelly B, Bismar TA: SPINK1 expression in relation to PTEN and ERG in matched primary and lymph node metastatic prostate cancer: Implications for biomarker development. Urol Oncol 2016, 34(5):235 e231-210.

28. Guedes LB, Tosoian JJ, Hicks J, Ross AE, Lotan TL: PTEN Loss in Gleason Score 3 + 4 = 7 Prostate Biopsies is Associated with Nonorgan Confined Disease at Radical Prostatectomy. J Urol 2017, 197(4):1054-1059.

29. Lotan TL, Carvalho FL, Peskoe SB, Hicks JL, Good J, Fedor H, Humphreys E, Han M, Platz EA, Squire JA et al: PTEN loss is associated with upgrading of prostate cancer from biopsy to radical prostatectomy. Mod Pathol 2015, 28(1):128-137.

30. Reid AH, Attard G, Ambroisine L, Fisher G, Kovacs G, Brewer D, Clark J, Flohr P, Edwards S, Berney DM et al: Molecular characterisation of ERG, ETV1 and PTEN gene loci identifies patients at low and high risk of death from prostate cancer. British journal of cancer 2010, 102(4):678-684.

31. Yoshimoto M, Joshua AM, Cunha IW, Coudry RA, Fonseca FP, Ludkovski O, Zielenska M, Soares FA, Squire JA: Absence of TMPRSS2:ERG fusions and PTEN losses in prostate cancer is associated with a favorable outcome. Mod Pathol 2008.

32. Lippolis G, Edsjo A, Stenman UH, Bjartell A: A high-density tissue microarray from patients with clinically localized prostate cancer reveals ERG and TATI exclusivity in tumor cells. Prostate Cancer 
Prostatic Dis 2013, 16(2):145-150.

33. Tomlins SA, Rhodes DR, Yu J, Varambally S, Mehra R, Perner S, Demichelis F, Helgeson BE, Laxman $\mathrm{B}$, Morris DS et al: The role of SPINK1 in ETS rearrangement-negative prostate cancers. Cancer Cell 2008, 13(6):519-528.

34. Ateeq B, Tomlins SA, Laxman B, Asangani IA, Cao Q, Cao X, Li Y, Wang X, Feng FY, Pienta KJ et al: Therapeutic targeting of SPINK1-positive prostate cancer. Sci Transl Med 2011, 3(72):72ra17.

35. Han B, Mehra R, Suleman K, Tomlins SA, Wang L, Singhal N, Linetzky KA, Palanisamy N, Zhou M, Chinnaiyan AM et al: Characterization of ETS gene aberrations in select histologic variants of prostate carcinoma. Mod Pathol 2009, 22(9):1176-1185.

36. Vinceneux A, Bruyere F, Haillot O, Charles T, de la Taille A, Salomon L, Allory Y, Ouzaid I, Choudat L, Roupret $\mathrm{M}$ et al: Ductal adenocarcinoma of the prostate: Clinical and biological profiles. Prostate 2017, 77(12):1242-1250.

37. Patil PA, McKenney JK, Reynolds JP, Przybycin CG, Magi-Galluzzi C: Clinical significance and EZH2, ERG and SPINK1 protein expression in pure and mixed ductal adenocarcinoma of the prostate. Histol Histopathol 2019, 34(4):381-390.

38. Leinonen KA, Tolonen TT, Bracken H, Stenman UH, Tammela TL, Saramaki OR, Visakorpi T: Association of SPINK1 expression and TMPRSS2:ERG fusion with prognosis in endocrine-treated prostate cancer. Clinical cancer research : an official journal of the American Association for Cancer Research 2010, 16(10):2845-2851.

39. Huang KC, Evans A, Donnelly B, Bismar TA: SPINK1 Overexpression in Localized Prostate Cancer: a Rare Event Inversely Associated with ERG Expression and Exclusive of Homozygous PTEN Deletion. Pathol Oncol Res 2017, 23(2):399-407.

40. Bhalla R, Kunju LP, Tomlins SA, Christopherson K, Cortez C, Carskadon S, Siddiqui J, Park K, Mosquera JM, Pestano GA et al: Novel dual-color immunohistochemical methods for detecting ERGPTEN and ERG-SPINK1 status in prostate carcinoma. Mod Pathol 2013, 26(6):835-848.

41. Hilal L, Shahait M, Mukherji D, Charafeddine M, Farhat Z, Temraz S, Khauli R, Shamseddine A: Prostate Cancer in the Arab World: A View From the Inside. Clin Genitourin Cancer 2015, 13(6):505511.

42. Darnel AD, Lafargue CJ, Vollmer RT, Corcos J, Bismar TA: TMPRSS2-ERG fusion is frequently observed in Gleason pattern 3 prostate cancer in a Canadian cohort. Cancer Biol Ther 2009, 8(2):125130.

43. Dong J, Xiao L, Sheng L, Xu J, Sun ZQ: TMPRSS2:ETS fusions and clinicopathologic characteristics of prostate cancer patients from Eastern China. Asian Pac J Cancer Prev 2014, 15(7):3099-3103.

44. Khani F, Mosquera JM, Park K, Blattner M, O'Reilly C, MacDonald TY, Chen Z, Srivastava A, Tewari AK, Barbieri CE et al: Evidence for molecular differences in prostate cancer between African American and Caucasian men. Clin Cancer Res 2014, 20(18):4925-4934.

45. Shan J, Al-Rumaihi K, Chouchane K, Al-Bozom I, Rabah D, Farhat K, Chouchane L: Prostate cancer small non-coding RNA transcriptome in Arabs. J Trans/ Med 2017, 15(1):260. 
46. Bismar TA, Hegazy S, Feng Z, Yu D, Donnelly B, Palanisamy N, Trock BJ: Clinical utility of assessing PTEN and ERG protein expression in prostate cancer patients: a proposed method for risk stratification. J Cancer Res Clin Oncol 2018, 144(11):2117-2125.

47. Attard G, Swennenhuis JF, Olmos D, Reid AH, Vickers E, A'Hern R, Levink R, Coumans F, Moreira J, Riisnaes $\mathrm{R}$ et al: Characterization of ERG, AR and PTEN gene status in circulating tumor cells from patients with castration-resistant prostate cancer. Cancer research 2009, 69(7):2912-2918.

48. Marrone M, Potosky AL, Penson D, Freedman AN: A 22 Geneexpression Assay, Decipher(R) (GenomeDx Biosciences) to Predict Five-year Risk of Metastatic Prostate Cancer in Men Treated with Radical Prostatectomy. PLoS Curr 2015, 7.

49. Flavin R, Pettersson A, Hendrickson WK, Fiorentino M, Finn S, Kunz L, Judson GL, Lis R, Bailey D, Fiore C et al: SPINK1 protein expression and prostate cancer progression. Clin Cancer Res 2014, 20(18):4904-4911.

50. Ornish D, Magbanua MJ, Weidner G, Weinberg V, Kemp C, Green C, Mattie MD, Marlin R, Simko J, Shinohara $\mathrm{K}$ et al: Changes in prostate gene expression in men undergoing an intensive nutrition and lifestyle intervention. Proc Natl Acad Sci U S A 2008, 105(24):8369-8374.

\section{Figures}



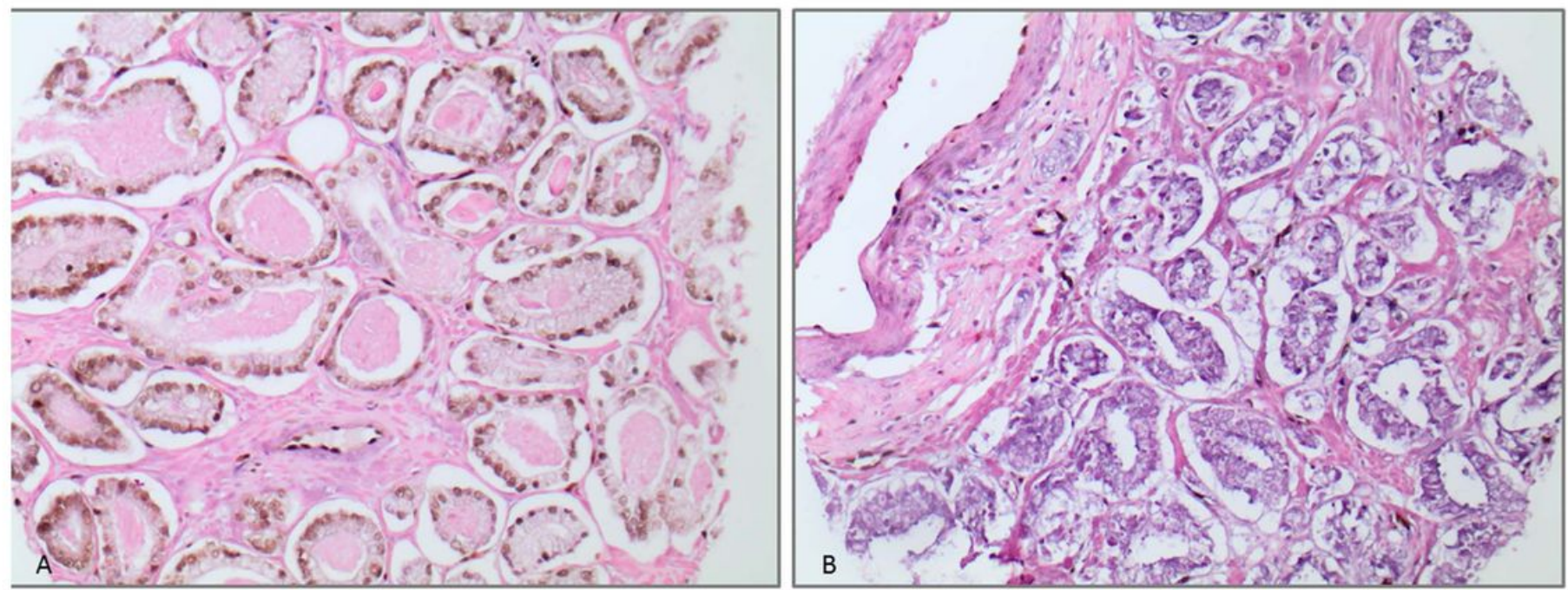

Figure1 (C-D)
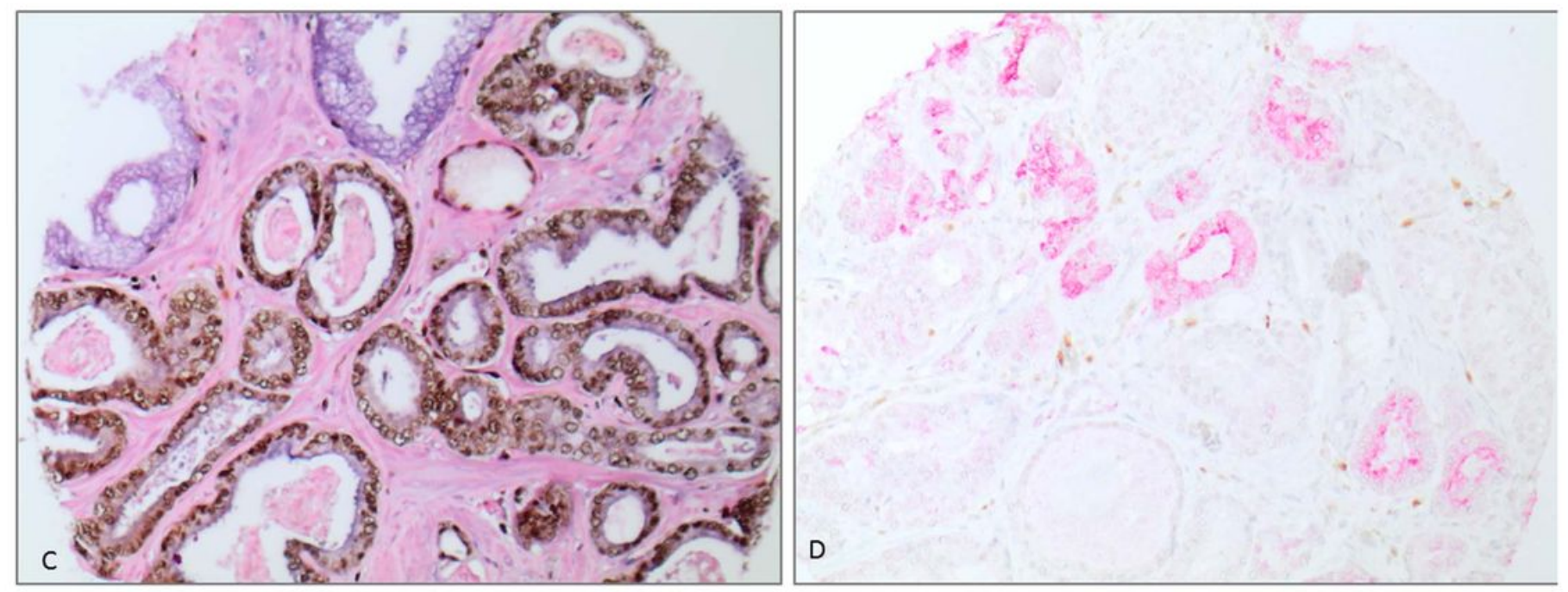

Figure 1

A, Immunohistochemistry for ERG positive (brown) and PTEN negative in Gleason grade group 1. B, Immunohistochemistry for PTEN positive (purple) and ERG negative in Gleason grade group 1 (note endothelial cells staining brown for ERG acting as internal control). C, Immunohistochemistry for ERG positive (brown) and PTEN positive (purple) in Gleason grade group 1. D, Immunohistochemistry for SPINK1 positive (red) and ERG negative in Gleason grade group 1 (note endothelial cells staining brown for ERG acting as positive control). 